\title{
Resenha Crítica: A Literatura Convencional Sobre Crises Financeiras nos Países "Emergentes": Os Modelos Desenvolvidos nos Anos 90
}

Daniela Magalhães Prates

\author{
Professora do Instituto de Economia (IE) da Unicamp e \\ pesquisadora do Cecon (Centro de Estudos de Conjuntura \\ e Política Econômica do IE)
}

\section{RESUMO}

As sucessivas crises financeiras dos países "emergentes", na segunda metade dos anos 90 , despertaram o interesse dos economistas do mainstream, uma vez que os modelos de crises cambiais de primeira geração, desenvolvidos nos anos 80 , revelaram-se insuficientes para a compreensão destes eventos. Nesse contexto, foram desenvolvidos novos modelos que incorporaram, como condicionantes destas crises, fatos estilizados, que têm caracterizado o sistema financeiro internacional contemporâneo, dentre os quais os ataques especulativos auto-realizáveis e o comportamento de manada dos investidores estrangeiros. Este artigo pretende apresentar as principais características desses novos modelos. Primeiramente, apresentam-se os modelos desenvolvidos após a crise mexicana, que seguiram a tradição dos modelos de segunda geração desenvolvidos após a crise do Sistema Monetário Europeu. Em seguida, são examinados os modelos que surgem após a crise asiática, denominados "modelos de terceira geração", nos quais a crise cambial está intrinsecamente associada a uma crise bancária. Seguem-se algumas considerações finais.

\section{PALAVRAS-CHAVE}

modelos de crises cambiais, crises financeiras, países "emergentes", fluxos de capitais

ABSTRACT

In the 90s, the succession of financial crises in the so called "emergent countries", with characteristics that haven't been considered by the first-generation models of exchange crises developed in the 80s, was followed by the emergency of new models of exchange crisis. The purpose of this article is to present these models, which have introduced in their analytical framework new elements, how the self-fulfilling expectations and the volatility of the capital flows. Firstly, we analyze the models developed after the Mexican crise, which have

followed the tradition of the second-generation models that emerged after the European monetary system crise. Secondly, we examine the models developed after the Asian crise, la-

beled "third generation models", in which the exchange crise is intrinsically linked with a banking crise. We end up with some final considerations.

KEY WORDS models of exchange crises, financial crises, "emergent" countries, capital flows

JEL Classification

F3IO, F4IO 


\section{INTRODUÇÃO}

As sucessivas crises financeiras ${ }^{1}$ dos países "emergentes" ${ }^{\text {"2 }}$ na segunda metade da década de 90 despertaram o interesse dos economistas do mainstream. ${ }^{3}$ Como reconheceram estes economistas, os modelos de crises cambiais desenvolvidos nos anos 80 , conhecidos como modelos de primeira geração, revelaram-se insuficientes para a compreensão destes eventos, que apresentaram características até então praticamente ignoradas pela literatura convencional, como imprevisibilidade e desvinculação com os fundamentos fiscais e monetários dos países.

Nesse contexto, ocorreu uma verdadeira "reação teórica" no âmbito desta literatura. (CUNHA e PRATES, 1999). Os teóricos do mainstream passaram a introduzir nos seus modelos fatores externos aos países como condicionantes destas crises, de forma geral, fatos estilizados que têm caracterizado o sistema financeiro internacional contemporâneo. Dentre esses fatos, os quais se manifestaram tanto na crise mexicana de dezembro de 1994 quanto na crise asiática de 1997, destacam-se: os ataques especulativos auto-realizáveis; a volatilidade dos fluxos de capitais; o comportamento de manada dos investidores estrangeiros; e o efeito-contágio. ${ }^{4}$

Este artigo pretende apresentar as principais fases e características desta "reação teórica”. Na primeira fase, iniciada logo após a crise mexicana, surgiram novos modelos de crises cambiais, que seguiram a tradição dos modelos de segunda geração desenvolvidos em resposta à crise do Sistema Monetário Europeu (SME), objeto da seção 2. Na segunda fase, deslanchada após a crise asiática, emergem os modelos de terceira geração, nos quais as crises cambiais estão intrinsecamente associadas a uma crise bancária que, por sua vez, pode se agravar por causa da crise cambial. Assim, esses modelos,

1 Entende-se por crise financeira qualquer crise que atinja um ou vários segmentos dos mercados financeiros, envolvendo assim crises cambiais, bancárias, gêmeas e financeiras internas. (WYPLOSZ, 1998).

2 Neste artigo, o termo países "emergentes" refere-se aos países periféricos capitalistas que receberam a maior parte dos fluxos de capitais provenientes dos países centrais nos anos 90.

3 Aqui, os termos mainstream e literatura convencional são utilizados como sinônimos, e adota-se a definição de mainstream economics de COLANDER, HOLT \& ROSSER (2003). De acordo com esses autores, este termo refere-se às idéias que a elite da profissão - os economistas líderes dos principais centros de graduação em economia - consideram aceitáveis, constituindo, assim, um termo mais amplo que ortodoxia que consiste na escola de pensamento dominante num determinado período histórico (no contexto atual, a economia neoclássica). No âmbito do mainstream, novas ideais e abordagens - que não se enquadram na ortodoxia - podem ser aceitas desde que sejam passíveis de modelagem. Nas palavras dos autores: "If isn' $t$ modeled, it isn't economics, no matter how insightful." (COLANDER, HOLT \& ROSSER, 2003, p. 8). Já o termo heterodoxia seria definido mais pelo que ele não é (ou seja, pela rejeição à ortodoxia) do que pelo que ele é (dada a diversidade de escolas heterodoxas). E, mesmo que membros da heterodoxia e economistas do mainstream compartilhem visões semelhantes sobre as limitações da ortodoxia, os heterodoxos não se enquadram no mainstream devido à modelagem utilizada e/ou às hipóteses assumidas nos modelos.

4 Vale mencionar que alguns economistas de orientação heterodoxa já enfatizavam o papel potencialmente instabilizador desses fatores. Ver, por exemplo: AKYÜZ (1992), FELIX (1994) e SHOR (1994). 
apresentados na seção 3, também poderiam ser denominados de "modelos de crises gêmeas". Seguem-se algumas consideraçôes finais.

\section{OS MODELOS DE CRISES CAMBIAIS DE PRIMEIRA GERAÇÃO}

O modelo canônico ${ }^{5}$ de primeira geração, desenvolvido originalmente por Krugman (1979), foi uma resposta às crises dos países dos latino-americanos do final dos anos 70 e início dos 80 . Este modelo sustenta, a partir de uma estrutura simples - previsão perfeita e equilíbrio único - que as crises cambiais são o resultado previsível de ataques especulativos inevitáveis, que resultam da resposta racional dos agentes privados a políticas domésticas inconsistentes. A inconsistência decorre da combinação de uma política de câmbio fixo com uma política fiscal expansionista financiada por emissão monetária. ${ }^{6}$ Antes de resumir a dinâmica desse modelo, é importante mencionar suas hipóteses simplificadoras (como reconhece o próprio Krugman), que podem ser separadas em dois grupos: hipóteses gerais e hipóteses relacionadas especificamente aos mercados cambial e monetário.

As hipóteses gerais são: país pequeno que produz somente um bem comercializável, cujo preço é determinado no mercado internacional, ou seja, depende da Paridade Poder de Compra (PPC); pleno emprego e preços e salários flexíveis; as expectativas são racionais no sentido forte, isto é, além dos agentes serem racionais há previsibilidade perfeita (mundo de certeza) ${ }^{7}$ o que implica inflação esperada igual à realizada e paridade não coberta de taxa de juros.

Já o segundo grupo inclui as seguintes hipóteses: no âmbito do mercado cambial, a taxa de acumulação de moeda estrangeira corresponde ao saldo da balança comercial, ou seja, não existe conta de capital; no âmbito do mercado monetário, a oferta de moeda doméstica corresponde à base monetária, ou seja, à emissão primária de moeda pelo banco central, pois não existem bancos privados; esta oferta cresce a uma taxa constante para financiar o déficit fiscal; os investidores estrangeiros não detêm moeda doméstica e os residentes podem alocar sua riqueza real entre dois tipos de ativos moeda doméstica e moeda estrangeira -, cujo rendimento nominal é nulo.

5 A expressão "modelo canônico" passou a ser utilizada na literatura de crises cambiais como sinônimo de modelo de referência.

6 O modelo seminal de KRUGMAN (1979) constitui uma adaptação para a literatura de crises cambiais do modelo de estabilizaçáo de preços de commodities, com estoque esgotável, desenvolvido por SALANT \& HENDERSON (1978). Mas, no modelo de Krugman o recurso esgotável são as reservas cambiais do banco central e o preço que deve ser sustentado é a taxa de câmbio.

7 SHEFFRIN (1983) esclarece as diferenças entre os dois tipos de expectativas racionais (nos sentidos forte e fraco). 
A dinâmica do modelo depende da interação entre as ações dos agentes que atuam no mercado monetário: o banco central e o setor privado doméstico não-financeiro, dada a inexistência de investidores estrangeiros e de bancos. O banco central fixa o preço da sua moeda em relação à moeda do maior parceiro comercial do país e utiliza seu estoque de moeda estrangeira para sustentar este preço, o que equivale a estabilizar o nível de preços domésticos, dada a hipótese de PPC. Os investidores residentes alocam sua riqueza real entre moeda doméstica e estrangeira dependendo da condição de equilíbrio de portfólio: enquanto esses investidores acreditarem que o governo vai continuar fixando a taxa de câmbio (e, assim, o nível de preço), a expectativa de inflação será nula e haverá uma relação estável entre os estoques de riqueza e de moeda doméstica. Em outras palavras, os residentes desejarão aumentar a detenção de moeda doméstica somente se lhes for oferecida uma maior taxa de rendimento na forma de uma inflação mais baixa.

Dado o compromisso do governo de fixar a taxa de câmbio, ele não tem controle sobre a forma de financiamento do seu déficit, uma vez que a demanda de moeda doméstica do setor privado é estável, dada a condição de equilíbrio de portfólio. Se o governo emite mais moeda que os investidores privados desejam reter, estes trocam o estoque adicional por reservas, que decrescem a um ritmo proporcional à taxa de crescimento da base monetária. Ou seja, esta base cresce a uma taxa constante para financiar o déficit fiscal do governo e a autoridade monetária não pode contrabalançar a variação das reservas por variações da oferta primária de moeda, ou seja, não pode esterilizar o fluxo de reservas.

Assim, quando o governo é deficitário - uma das hipóteses centrais do modelo - a manutenção da paridade é impossível, independentemente do estoque inicial de reservas cambiais. Num determinado momento, o problema de balanço de pagamentos (perda gradual de reservas) transforma-se numa crise: os agentes racionais, antecipando que sem especulação as reservas atingirão o patamar mínimo (forçando o abandono da paridade), procuram adquirir o estoque de moeda estrangeira do governo. A crise sempre advém antes que esse estoque tenha se esgotado.

Se os investidores não antecipam o ataque, quando as reservas se esgotam o nível de preços torna-se a variável de ajuste: o equilíbrio de portfólio do setor privado passará a determinar este nível e não mais o estoque de moeda doméstica. Devido ao excesso de oferta vis-à-vis à demanda de moeda, o nível de preços começa a aumentar (dadas as hipótese de pleno emprego e preços e salários flexíveis), o que implica queda da demanda de moeda. Ou seja, se não existe especulação, o esgotamento das reservas sempre resultará em aumento discreto da taxa de câmbio (dado o desequilíbrio entre oferta e demanda de moeda estrangeira) e do nível de preços (dada a PPC), provocando uma perda de capital para os especuladores. 
Contudo, como os investidores são racionais e antecipam corretamente os eventos (dada a hipótese de previsibilidade perfeita), eles evitarão esta perda de capital. Se o estoque de moeda doméstica é trocado por moeda estrangeira um instante antes das reservas se esgotarem, os especuladores podem obter uma taxa de lucro infinita. Todavia, numa situação de equilíbrio com previsão perfeita, nem ganhos nem perdas de capital a uma taxa infinita são possíveis. Os especuladores, prevendo o ganho de capital, competem entre si para apropriá-lo (tentando livrar-se o mais rapidamente possível da moeda doméstica), mas esta competição acaba eliminando as oportunidades de lucro. $\mathrm{Na}$ realidade, o ataque especulativo contra as reservas do governo permite aos investidores evitarem perdas de capital. ${ }^{8}$

A partir de meados dos anos 80, vários autores procuraram estender ou adaptar o modelo canônico com o objetivo de torná-lo menos estilizado, a partir da introdução de características geralmente presentes nas crises de balanço de pagamentos dos países em desenvolvimento nos anos 80. (BERG et al., 1999). Dentre essas características, destacam-se: a incerteza ${ }^{9}$ em relação ao nível de reservas e à política monetária do governo; a substitutibilidade imperfeita de ativos e os preços rígidos; os efeitos reais das crises antecipadas; e o papel dos controles de capitais. (AGÉNOR, BHANDARI \& FLOOD, 1992). ${ }^{10}$

Além desses modelos, foram igualmente desenvolvidos modelos que anunciaram algumas questões que seriam exploradas pela literatura convencional sobre crises cambiais nos anos 90: o modelo de Obstfeld (1986) e o modelo de Velasco (1987).

O modelo de Obstfeld (1986) introduziu o papel das expectativas auto-realizáveis na explicação das crises cambiais e, assim, pode ser considerado o "germe" dos modelos de segunda geração, desenvolvidos após a crise do SME, como se destacará a seguir. O ponto de partida deste autor é o questionamento de uma das hipóteses centrais do modelo canônico: de que os agentes não esperam nenhuma mudança da política monetária após a crise. No seu modelo, a política monetária após a crise não é necessariamente a mesma, mas passa a depender da ocorrência ou não do ataque especulativo. Se os agentes esperam que seja adotada uma política monetária inflacionista após a crise, eles realizam o ataque e as autoridades validam ex post essas expectativas mediante uma expansão mais intensa da oferta primária de moeda. Neste caso, a profecia auto-realizável

8 Krugman não derivou explicitamente uma solução para o momento exato do ataque especulativo, tendo somente anunciado um resultado "intuitivo": quanto maior o estoque inicial de reservas e menor a taxa de expansão da oferta primária de moeda, mais tardio será o ataque. Num artigo posterior, FLOOD \& GARBER (1984) introduzem o conceito de "taxa de câmbio sombra", o qual permite a solução para o momento exato do ataque especulativo. (AGÉNOR, BHANDARI \& FLOOD, 1992). Por isso, o modelo canônico também é conhecido como modelo "Krugman-Flood-Garber".

9 Na teoria convencional, o termo "incerteza" é sinônimo de risco probabilístico.

10 Para um resumo desses modelos, ver AGÉNOR, BHANDARI \& FLOOD (1992). 
se verifica, e a crise eclode. Caso contrário, a moeda não é atacada e as autoridades mantêm a paridade fixa e a regra de expansão monetária adotada até então. Ou seja, existem dois equilíbrios possíveis em previsão perfeita - o equilíbrio com crise e o equilíbrio sem crise - mas o resultado do modelo é indeterminado. ${ }^{11}$

Já Velasco (1987) anuncia a relação entre crises cambiais e bancárias, que passou a ser enfatizada após as crises mexicana e, principalmente, asiática. Este autor procura formalizar a análise de Diaz-Alejandro (1985) sobre a crise dos países do Cone Sul do início dos anos 80, a partir da extensão do modelo de primeira geração de Krugman (1979) para uma situação na qual o sistema bancário é explicitamente considerado. Em seu modelo, um choque externo negativo reduz o valor dos ativos bancários. Contudo, em razão da existência de garantias aos depósitos, os bancos não liquidam os empréstimos de má qualidade, mas recorrem aos créditos externos para cobrir as perdas. Quando o acesso a esses recursos é interrompido, o governo intervém e resgata os bancos. Os custos desse resgate e a socialização dos passivos externos dos bancos resultam no esgotamento das reservas cambiais e no colapso da paridade. Assim, o crescimento excessivo da oferta monetária (nesse modelo, sinônimo de crédito doméstico) não decorre do déficit fiscal, mas dos esquemas de garantia pública ao sistema bancário.

\section{A LITERATURA DE CRISES CAMBIAIS DE SEGUNDA GERAÇÃO}

A literatura de primeira geração sofreu seu primeiro abalo com as crises do SME de 1992-93. Em primeiro lugar, ao contrário das crises previsíveis e antecipadas desses modelos, estas crises foram, em grande medida, inesperadas e aparentemente inexplicáveis, diante dos sólidos fundamentos fiscais e monetários dos países. Em segundo lugar, a decisão de abandonar a paridade fixa nesse contexto não decorreu da exaustão inevitável das reservas internacionais, provocada pelo desequilíbrio fiscal, mas da relutância dos governos em enfrentar o ataque especulativo, realizado tanto por investidores residentes quanto por não-residentes, mediante elevadas taxas de juros. (BERG et al., 1999 e FLOOD \& MARION, 1998).

Os modelos desenvolvidos após a crise do SME, denominados de modelos de segunda geração, ${ }^{12}$ procuram fornecer uma explicação para esse novo padrão de crise, a partir do abandono de várias hipóteses dos modelos de primeira geração, dentre as quais: previsibilidade e inevitabilidade dos ataques especulativos; a participação exclusiva dos

11 Esse modelo é um modelo de equilíbrio múltiplo. Além do modelo de OBSTFELD (1986), vários modelos de crises financeiras desenvolvidos nos anos 90 têm como característica a multiplicidade de soluções, como se verá nas duas próximas seções.

12 Esta tipologia de modelos, que se tornou hegemônica, foi feita por EICHEENGREN, ROSE \& WYPLOSZ (1995). 
investidores residentes nesses ataques; e a ausência dos fluxos de capitais, bem como dos sistemas financeiros domésticos. É possível identificar dois tipos de modelos de segunda geração. (FLOOD \& MARION, 1998).

O primeiro tipo são os modelos de ataques especulativos auto-realizáveis (por exemplo, EICHENGREEN, ROSE \& WYPLOSZ, 1995) - cuja paternidade é o modelo de Obstfeld (1986) - nos quais mudanças na política monetária condicionadas pelo ataque especulativo podem resultar numa crise auto-realizável, mesmo que as políticas monetária e fiscal correntes sejam compatíveis com o regime de câmbio fixo. Os novos modelos procuram preencher a lacuna daquele modelo - a inexistência de uma explicação para as expectativas de adoção de uma política monetária inflacionista após a crise, que resultam no ataque especulativo auto-realizável - a partir da adoção de uma definição mais ampla dos fundamentos, que inclui, além dos fundamentos tradicionais ou "estreitos" (políticas fiscais e monetárias correntes), todas as variáveis exógenas que influenciam as antecipaçóes dos agentes atuantes no mercado de câmbio sobre a política monetária futura do governo, como o nível de desemprego, o grau de endividamento do setor público e a situação do sistema bancário. Assim, apesar da compatibilidade dos fundamentos "estreitos" com o regime de câmbio fixo, os agentes passam a questionar sua sustentabilidade diante da degradação dos fundamentos "ampliados" e realizam um ataque especulativo, que é sancionado pelas autoridades. (JEANNE, 1996).

No segundo tipo de modelo, os modelos de "cláusula de escape", as expectativas autorealizáveis e os fundamentos “ampliados” também estão presentes, mas há uma mudança de foco da análise: o comportamento do setor privado e das reservas cambiais, que determinam a dinâmica dos modelos de ataques especulativos auto-realizáveis, é mantido em segundo plano, e a ênfase é colocada na racionalidade das decisóes de política econômica do governo. A questão fundamental a ser enfrentada pelo governo é permanecer ou não no sistema de câmbio fixo (ou seja, desvalorizar ou não), e esta decisão deverá ser tomada em função dos seus objetivos mais gerais e do contexto macroeconômico, que inclui não somente a situação fiscal, mas um conjunto mais amplo de variáveis, isto é, os fundamentos "ampliados". Foi esse tipo de modelo, desenvolvido originalmente por Obstfled (1994), que se tornou referência na literatura de segunda geração.

Assim, na segunda geração de modelos a crise cambial constitui o resultado não antecipado de mudanças auto-realizáveis nas expectativas do mercado. Mesmo um país com fundamentos monetários e fiscais sólidos pode ser vítima de um ataque especulativo. Mas isto não quer dizer que a probabilidade e a eficácia do ataque não tenham relação com os fundamentos. Este ataque é bem-sucedido, resultando na eclosão da crise, somente se existir uma região de fundamentos "fracos", que incluem um leque mais amplo de variáveis (além das políticas fiscal e monetária, a taxa de desemprego, a situação 
do sistema bancário, o nível de endividamento do setor público), na qual os custos de defender a paridade são tão altos que o ataque especulativo auto-realizável torna-se inevitável. (BERG et al., 1999).

Igualmente, nesses modelos não há mais uma relação determinística entre os fundamentos (agora "ampliados") e a crise, uma vez que existem dois equilíbrios possíveis se o país encontra-se na "região frágil": o equilíbrio com ataque especulativo (quando a crise auto-realizável ocorre) e o equilíbrio sem ataque (e, assim, sem crise). A crise pode jamais acontecer se os agentes se coordenarem no equilíbrio sem ataque. Ou seja, ao contrário dos modelos de primeira geração, com equilíbrio único, existe a possibilidade de equilíbrios múltiplos. ${ }^{13}$

Os modelos de segunda geração, principalmente os modelos de "cláusula de escape", serviram de base para a primeira "onda" de modelos de crises cambiais nos países “emergentes" desenvolvidos nos anos 90, que surgiu logo após a crise do México de 1995, como se verá na próxima subseção.

\subsection{Os Modelos de Segunda Geração "Aplicados" aos Paises "Emergentes}

Os modelos desenvolvidos após a crise mexicana procuraram incorporar as "lições" dessa crise para a teoria. Além de não apresentar a inconsistência nos fundamentos "estreitos” destacada pelos modelos de primeira geração, essa crise apresentou características ignoradas por esses modelos. Como ressaltam Calvo et al. (1996), na apresentação do número especial do Journal of International Economics, "Speculative attacks in emerging markets: what Mexico taught us?": "a broad consensus emerged that Mexico's crisis contains critical elements that are not highlighted by the conventional wisdom."

Este número incluiu novos modelos de crise cambiais, dentre os quais destacam-se os de Sachs, Tornell \& Velasco (1996a), Calvo e Mendoza (1996) e Cole \& Kehoe (1996). Esses modelos seguem a abordagem analítica dos modelos de segunda geração desenvolvidos após a crise do SME, mas aplicada ao caso dos países "emergentes”. Diversos elementos foram incorporados na explicação das crises desses países: as expectativas auto-realizáveis dos investidores residentes e não-residentes; a influência de um

13 A multiplicidade de soluções decorre das regras de comportamento não-linear dos agentes. Enquanto os modelos de primeira geração combinam regras de comportamento linear do setor privado e do governo, os modelos de segunda geração enfatizam potenciais não-linearidades no comportamento do governo. (FLOOD \& MARION, 1998). Os modelos com equilíbrio múltiplo, em razão de suas propriedades (principalmente, sua estrutura não-linear) revelaram-se mais adequados para a modelização dos fatos estilizados que têm caracterizado o mercado financeiro internacional nas últimas décadas e, assim, para a análise das crises financeiras recentes. (MASSON, 1999). Essas propriedades permitem que as expectativas sejam auto-realizáveis e possibilitam a introdução do chamado market sentiment nos modelos convencionais. Contudo, esses modelos em geral são indeterminados, pois não explicam por que os especuladores se coordenam no equilíbrio com ou sem ataque e, assim, ambos tipos de equilíbrio são igualmente prováveis. 
espectro mais amplo de fundamentos, que condicionam a decisão de desvalorizar ou não dos governos, como a fragilidade do sistema bancário, o papel das variáveis externas, sobretudo a política monetária dos países desenvolvidos; e o efeito-contágio. Assim, ao contrário dos modelos de primeira geração, os investidores estrangeiros detêm moeda doméstica e participam, ao lado dos residentes, do ataque especulativo auto-realizável; e os fluxos de capitais e o sistema bancário passam a ser considerados.

Além da mesma abordagem analítica, outra semelhança entre os modelos desenvolvidos pós-crise do SME e pós-crise do México refere-se ao leque de fundamentos "ampliados” considerado. No caso do México, esses fundamentos seriam o estoque elevado de dívida pública de curto prazo (tesobonus) nos portfólios dos investidores estrangeiros e a fragilidade do sistema bancário doméstico. Nos países membros do SME, esses fundamentos teriam variado entre os países, mas envolveriam igualmente esses dois fatores, além do alto nível de desemprego e das “incertezas" quanto ao Tratado de Maastricht. $^{14}$

Alguns modelos analisaram somente o papel do estoque de dívida pública de curto prazo, principalmente daquela parcela denominada em dólar (os tesobonus), na eclosão da crise cambial auto-realizável, como Cole \& Kehoe (1996) e Sachs, Tornell \& Velasco (1996a). A crise do México se diferenciaria das crises dos países latino-americanos dos anos 80, pois não teria sido o resultado de um comportamento fiscal irresponsável do governo. O setor público teria "entrado na cena" quando passou a esterilizar os efeitos monetários dos fluxos de capitais mediante emissão de títulos denominados em peso e, posteriormente, em dólares.

Nesses modelos, o crescimento desse estoque até um determinado patamar, num contexto de queda das reservas, conduz a economia para a "região frágil”, na qual há possibilidade de "equilíbrio múltiplo": se os agentes esperam a desvalorização, esta será validada pelo governo, diante dos maiores custos de financiamento da dívida (devido à necessidade de elevação dos juros e do aumento do prêmio de risco dada a expectativa de desvalorização); caso contrário, esta não ocorrerá. Assim, o governo mexicano, apesar de solvente (em termos de uma baixa razão dívida/PIB), teria se tornado vulnerável a uma crise de liquidez, pois suas reservas líquidas não seriam suficientes para cobrir as obrigações de curto prazo. O fato de grande parte de essas obrigações serem denominadas em moeda estrangeira teria agravado essa vulnerabilidade, pois o banco central, neste caso, não poderia atuar como emprestador em última instância.

14 Como ressalta OBSTFELD (1994), a crise dos países nórdicos no início dos anos 90 teria decorrido do dilema entre a manutenção de uma taxa de câmbio fixa e os efeitos que um aumento da taxa de juros teria sobre o sistema bancário fragilizado. Já problema da estrutura de maturidade e da denominação monetária da dívida pública também estaria subjacente à crise da lira italiana em 1992. 
De acordo com Sachs, Tornell \& Velasco (1996a), dois fatores indicavam a necessidade de ajustes na política econômica: a sobrevalorização do peso e o amplo déficit em conta corrente. Este contexto e os conflitos políticos do início de 1994 explicariam a retração dos fluxos de capitais. Contudo, nesse momento, quando o nível de reservas ainda era elevado e o volume de dívida de curto prazo denominada em moeda estrangeira reduzido, um ajustamento gradual seria possível e envolveria, além de uma correção da taxa de câmbio, políticas fiscal e monetária mais restritivas. Mas o governo mexicano teria optado, na realidade, por uma política monetária expansionista - que acentuou a queda de reservas associada à redução dos ingressos de capital - e pela substituição progressiva dos Certificados de la Tesorería de la Federación (Cetes), títulos de curto prazo sem correção cambial, pelos Tesobonus.

Mas quais teriam sido as razões subjacentes à opção de política econômica do governo mexicano ao longo de 1994? Num texto precedente (SACHS, TORNELL \& VELASCO, 1996b), estes autores explicitam o conflito entre os múltiplos objetivos do governo mexicano, que teria condicionado esta opção. Por um lado, ajustes na política cambial (leia-se, desvalorização) teriam sido descartados devido ao receio de perda de credibilidade num ano eleitoral. Por outro lado, a fragilidade do sistema bancário, expressa no volume expressivo de créditos em atraso e liquidação nos portfólios dos bancos, teria impedido a autoridade monetária de praticar uma política monetária restritiva, a qual teria evitado a evasão das reservas ao longo de 1994. Assim o banco central teria neutralizado a queda das reservas provocada pela saída de capitais mediante aquisição de títulos detidos pelas instituições financeiras, o que resultou na expansão da oferta de moeda (também sinônimo de crédito doméstico nesse modelo).

A fragilização do sistema bancário estaria, por sua vez, associada ao contexto de liberalização financeira doméstica e absorção de fluxos de capitais. Esta liberalização financeira, que eliminou os encaixes compulsórios, ao lado da queda da inflação, teria resultado no aumento do grau de monetização da economia e, assim, dos depósitos bancários, que possibilitou a expansão excessiva do crédito bancário. Os fluxos de capitais, em grande medida intermediados pelos bancos, fomentaram o ciclo de crédito, direcionado, sobretudo, para o consumo e a aquisição de imóveis. O resultado dessa expansão foi a deterioração dos ativos dessas instituiçóes, que teria condicionado a decisão do governo mexicano de adotar uma política monetária laxista em 1994.

Os autores mencionam outra fonte de vulnerabilidade da economia mexicana, associada igualmente ao aumento do grau de monetização: o elevado volume de depósitos bancários de curto prazo vis-à-vis às reservas cambiais. Isto porque, dada a existência de reservas bancárias fracionárias e garantia pública implícita ou explícita aos depósitos, estes depósitos são obrigações contingentes do banco central, uma vez que os agentes esperam que o governo fornecerá liquidez para os bancos em dificuldade. Nesse con- 
texto, uma corrida bancária pode se converter facilmente numa fuga da moeda nacional. Assim, a vulnerabilidade da economia mexicana a um ataque especulativo autorealizável não decorreria somente da elevada dívida pública de curto prazo (como em COLE \& KEHOE, 1996 e SACHS, TORNELL \& VELASCO, 1996a), mas também da liquidez dos depósitos bancários, garantidos, em última instância, pelo governo.

A política alternativa - que teria evitado a crise na visão dos autores - seria a não-esterilização da queda das reservas, que provocaria uma elevação da taxa de juros devido ao desequilíbrio entre a demanda e oferta de moeda. Essa elevação resultaria numa contração dos gastos dos agentes privados e, assim, na redução do déficit em conta corrente. Em outras palavras, o Banco Central mexicano, ao esterilizar o impacto monetário contracionista da saída de capitais, teria evitado que o mecanismo de ajustamento clássico num regime de câmbio fixo entrasse em operação.

De acordo com Sachs, Tornell \& Velasco, a crise mexicana não teria sido uma crise cambial padrão, mas uma crise de liquidez do governo e, assim, não se encaixaria nos modelos de primeira geração: além de inesperada pela maioria dos agentes, a desvalorização e o pânico financeiro teriam sido eventos separados, lógica e temporalmente, com a desvalorização ocorrendo antes e contribuindo para o pânico em relação aos títulos públicos, ao gerar expectativas de que o governo não iria honrar suas obrigações denominadas em dólar. O contágio para o setor privado, em especial para o sistema bancário, decorreria da crença de que o governo, dada a sua situação da iliquidez, se veria impossibilitado de agir como emprestador em última instância, o que seria a regra nos países em desenvolvimento.

Calvo \& Mendoza (1996) também enfatizam os erros de política econômica ao longo de 1994, o desequilíbrio entre os agregados monetários (M2 e M3) e as reservas cambiais e o papel da fragilidade bancária na crise de dezembro. Segundo esses autores, essa crise seria um "novo tipo de crise de balanço de pagamentos, na era dos mercados de capitais globais”. No entanto, ao contrário de Sachs, Tornell \& Velasco (1996b), esses autores desenvolveram um modelo que combina elementos dos modelos de primeira e segunda geração. Assim, seu modelo pode ser considerado um modelo crossgeneration, ou seja, "intergerações". ${ }^{15}$ A crise estaria relacionada a dois mecanismos. O primeiro mecanismo associa a fragilidade bancária e os fluxos de capitais com a vulnerabilidade da paridade cambial e gera prediçôes similares aos modelos de primeira geração (redução gradual e, depois, súbita das reservas, quando a paridade é abandonada). Todavia, o ataque especulativo, subjacente à crise, não se originaria do

15 Essa denominação foi sugerida por FLOOD \& MARION (1996). É importante mencionar que nos anos 90, além do surgimento de novas gerações de modelos de crises cambiais, foram desenvolvidos modelos cross-generation e novos modelos de primeira geração, dando continuidade ao movimento de adaptação e extensão deste tipo de modelo iniciado nos anos 80 . 
déficit fiscal, como nesses modelos, mas da antecipação de um bail-out do sistema bancário pelo banco central, uma vez que esse sistema estaria fragilizado em virtude do acúmulo de créditos de liquidação duvidosa e do descasamento de prazos entre os passivos e os ativos - associados, respectivamente, ao boom creditício alavancado pelos fluxos de capitais num contexto de subestimação dos riscos cambiais, dado o regime de câmbio fixo, e ao aumento do grau de monetização da economia após a liberalização financeira e a estabilização dos preços.

Nesse contexto, a paridade cambial teria se tornado menos crível, pois os agentes teriam percebido que sua manutenção comprometeria a habilidade do banco central de atuar como emprestador em última instância. Ademais, a própria reação das autoridades monetárias mexicanas aos choques do início de 1994 teria abalado a confiança dos agentes na política cambial, pois, em vez de praticar uma política monetária restritiva necessária para reverter a queda das reservas e, assim, sustentar a paridade, optou-se pela esterilização da queda das reservas (aspecto também ressaltado por SACHS, TORNELL \& VELASCO, 1996), exatamente para evitar uma crise bancária. Assim, a fragilidade dos bancos constituiria um elemento fundamental para a compreensão da crise mexicana.

Contudo, a dimensão da crise após a flutuação da taxa de câmbio requer explicações adicionais. É necessário um segundo mecanismo que explique a relação entre a desvalorização cambial e a fuga maciça dos ativos domésticos. Para explicá-la, Calvo \& Mendoza anunciam um argumento que será desenvolvido, de forma mais detalhada, num artigo posterior: ${ }^{16}$ de acordo com esses autores, a mudança abrupta de opinião dos investidores globais sobre suas posições no México, que teria desencadeado o ataque especulativo bonds-led nos dias após a desvalorização, bem como o efeito-tequila, decorreria do seu comportamento de manada, que seria racional num contexto de crescente diversificação internacional propiciada pelos mercados de capitais globalizados. Nesse contexto, os investidores se tornariam extremamente suscetíveis a pequenos choques negativos ou boatos. A desvalorização mexicana teria sido um desses choques, que alterou as expectativas de lucro desses investidores ao sinalizar que o novo governo seria menos confiável que o anterior.

16 No modelo de CALVO \& MENDOZA (1997), que se baseia na abordagem do rational herding behaviorsegundo a qual o herding (comportamento de manada) decorre de um tipo de falha de mercado, as assimetrias de informação -, a globalização do mercado internacional de capitais, ao aumentar o leque de ativos disponíveis e assim possibilitar a diversificação dos portfólios dos investidores estrangeiros, reduziria, ao mesmo tempo, os retornos associados ao "investimento" na obtenção de informaçôes sobre os diversos ativos, acentuando o problema de informação incompleta que torna o herding racional. Neste contexto, os investidores tornar-se-iam extremamente suscetíveis a choques negativos de pequena magnitude e mesmo a boatos e o comportamento de manada seria o "resultado natural" da estratégia de otimização de seus portfólios num contexto de crescente diversificação internacional. Este problema de "ação coletiva" aumentaria a probabilidade de amplos movimentos dos fluxos de capitais desvinculados dos fundamentos e, assim, da eclosão de crises associadas ao contágio. 
Porém, este argumento não explica por que a situação não se estabilizou depois da queda abrupta dos preços das ações e dos títulos, que restaurou a rentabilidade dos ativos domésticos. O efeito do pânico inicial teria sido magnificado pelo grande estoque de tesobonus que estavam vencendo, que suscitou dúvidas quanto à solvência do governo. De acordo com os autores, nesse momento as "profecias auto-realizáveis" (a característica dos modelos de segunda geração introduzida no modelo) teriam entrado em ação: a opção do governo de refinanciar esse estoque a taxas de juros mais altas teria se frustrado devido às expectativas desfavoráveis dos investidores (diante da situação política tensa, do conflito de Chiapas etc.), que acabaram por forçá-lo a adotar um programa draconiano de ajuste para obter apoio internacional e, assim, evitar o default dos tesobonus.

Assim, pode-se dizer que nesses dois últimos modelos (SACHS, TORNELL \& VELASCO, 1996b e CALVO \& MENDOZA, 1996) a inconsistência intertemporal da política monetária - associada à fragilidade do sistema bancário e ao elevado estoque de dívida pública de curto prazo vis-à-vis às reservas cambiais - teria impedido o banco central de praticar uma política monetária compatível com a manutenção do regime de câmbio fixo e, conseqüentemente, tornado o país vulnerável a um ataque especulativo auto-realizável. Mas, apesar dos vários pontos em comum, o modelo de Calvo \& Mendoza dá um passo adicional em relação ao de Sachs, Tornell \& Velasco (1996b), ao fornecer uma rationale para a coordenação no equilíbrio com ataque e, assim, para o ataque especulativo auto-realizável: o comportamento de manada dos investidores estrangeiros num ambiente de mercados de capitais globalizados. ${ }^{17}$

Ademais, ambos os modelos já adiantam elementos que terão um papel central nos modelos de terceira geração, desenvolvidos após a crise asiática, como: a relação entre o contexto de ingresso de capitais e liberalização financeira doméstica e a fragilidade bancária, e o papel desta fragilidade no colapso do regime de câmbio fixo. Contudo, esses modelos não exploram, como a geração subseqüente, quais seriam os fatores específicos aos países "emergentes”, subjacentes à emergência da situação de fragilidade bancária neste contexto e ao vínculo entre esta fragilidade e a crise cambial. Somente mencionam, en passant, alguns destes fatores, como a função do banco central de emprestador em última instância e "garantidor" dos depósitos, ou seja, a existência de garantias públicas aos ativos e passivos bancários. ${ }^{18}$

17 Uma limitação dos modelos de equilíbrio múltiplo é exatamente a inexistência de uma explicação de por que os investidores se coordenam em um ou outro equilíbrio.

18 Após a crise mexicana, também proliferaram trabalhos teóricos e empíricos sobre as crises bancárias em geral, e nos países "emergentes", em particular, que procuraram investigar as causas subjacentes à fragilidade bancária desses países, questão não aprofundada pela literatura de crise cambial de segunda geração. Ver, por exemplo: DEMIRGÜÇ-KUNT \& DETRAGIACHE (1998); CAPRIO JR. \& KLINGEBIEL (1996); e MISHKIN (1996). 


\section{OS MODELOS DE TERCEIRA GERAÇÃO}

A crise do sudeste asiático abalou ainda mais a crença no poder explicativo dos modelos convencionais de crises cambiais e marcou o segundo momento de inflexão na literatura convencional sobre crises financeiras nos países "emergentes" ${ }^{19}$ Esta crise eclodiu em países com sólidos fundamentos fiscais e monetários e, assim, não poderia ser explicada a partir dos modelos de primeira geração. Igualmente, as autoridades monetárias desta região não enfrentavam um dilema da política decorrente da incompatibilidade do regime de câmbio fixo com os fundamentos macroeconômicos "ampliados" dos modelos de segunda geração, desenvolvidos pós-crise do SME, como um alto nível de desemprego e um estoque elevado de dívida pública de curto prazo. Pelo contrário, os países do sudeste asiático eram aclamados pela sua extraordinária capacidade de combinar fundamentos macroeconômicos estáveis com um elevado crescimento, sustentado por mais de duas décadas.

Esta crise foi uma crise financeira de caráter gêmeo, caracterizada pelo colapso simultâneo dos regimes de câmbio administrado e dos sistemas bancários domésticos após a reversão súbita dos fluxos de capitais. Contudo, ela também não se enquadra nos modelos desenvolvidos após a crise mexicana. Apesar de não terem ignorado o sistema bancário, nesses modelos este sistema foi inserido em "segundo plano". Na verdade, foi incorporado como um dos fundamentos "ampliados" que impóem um dilema às autoridades monetárias e condicionam a decisão do governo de abandonar ou não $o$ regime de câmbio fixo. Ademais, os determinantes da fragilidade bancária dos países "emergentes" não são examinados.

Nos modelos de terceira geração, que procuram explicar o novo padrão de crise que eclodiu no sudeste asiático, a ênfase se desloca dos fundamentos macroeconômicos "estreitos" ou "ampliados" para as características dos sistemas financeiros dos países "emergentes". A fragilidade desses sistemas torna-se o elemento central na explicação das crises cambiais, pois estas estão intrinsecamente associadas a uma crise bancária que, por sua vez, pode se agravar por causa da crise cambial. Ou seja, há uma interação entre as duas modalidades de crise. ${ }^{20}$ Assim, esses modelos também poderiam ser denominados de "modelos de crises gêmeas". A literatura de crises bancárias "entra em cena" ao fornecer os elementos para a compreensão das causas desta fragilidade, que explicaria a maior vulnerabilidade dos países "emergentes" vis-à-vis às economias desenvolvidas, a essas crises.

19 Sobre a "reação teórica" após a crise asiática, ver também CUNHA \& PRATES (2001 e 2003).

20 CANUTO \& CURADO (2002) também enfatizam essa característica da terceira geração de modelos, mas na tipologia adotada por esses autores esta geração também incluiria modelos nos quais a crise cambial está diretamente vinculada aos problemas de contágio entre os países. Um exemplo deste tipo de modelo é o modelo de CALVO \& MENDOZA (1997). 
É possível distinguir três grupos de modelos de terceira geração, que se diferenciam em relação tanto à explicação da origem da fragilidade dos sistemas financeiros "emergentes" quanto à abordagem analítica utilizada. No primeiro grupo (inclusive cronologicamente, tendo surgido logo após a crise asiática) estão os modelos que associam essas fragilidades ao risco moral criado pelas garantias governamentais, e seguem a tradição analítica dos modelos de primeira geração. No segundo grupo, a ênfase desloca-se do risco moral para o pânico financeiro e as expectativas auto-realizáveis dos investidores estrangeiros, e a abordagem analítica é semelhante à dos modelos de segunda geração. Já o terceiro grupo de modelos procura integrar os argumentos do risco moral e do pânico financeiro e segue, de forma geral, esta última abordagem. ${ }^{21}$ Como a literatura de terceira geração é bastante extensa, optou-se por selecionar um modelo representativo em cada grupo.

No primeiro grupo de modelos a crise é o resultado inevitável de um ataque especulativo antecipado contra as reservas do banco central, como nos de primeira geração. Contudo, nesses modelos, a inconsistência da política subjacente ao ataque especulativo antecipado e à crise inevitável está associada à existência de garantias públicas ao passivo externo do setor privado (e não mais aos desequilíbrios nos fundamentos fiscais e monetários), que geram distorções nos sistemas financeiros domésticos e na alocação interna dos recursos, e estimulam a absorção excessiva e insustentável de fluxos de capitais pelos agentes domésticos (bancos, instituições financeiras não-bancárias e empresas).

Alguns autores (KRUGMAN, $1998^{22}$ e CORSETTI, PESENTI \& ROUBINI, 1998) aplicaram esta análise para o caso específico dos países asiáticos, atacando as idiossincrasias do padrão de intervenção estatal na região: em um contexto de "capitalismo de compadres", os agentes internos e externos tomavam suas decisões de investimento e endividamento, em razão da crença de que a rentabilidade de seus investimentos e suas posições patrimoniais seriam sustentadas pelo Estado. Isto distorceria os sinais de mercado, o que teria implicado decisões equivocadas de alocação de recursos e uma situação de sobreinvestimento, sustentada pelo financiamento externo.

Já Dooley (1997) desenvolveu um modelo de crise financeira nos "mercados emergentes" em geral, baseado igualmente na abordagem analítica dos modelos de primeira geração e no argumento do moral hazard. Nesse modelo, denominado pelo autor de insurance mo-

21 EICHENGREEN (1999) questiona a existência de uma terceira geração de modelos, sugerida inicialmente por Krugman. Segundo este autor, os novos modelos seriam casos particulares dessas abordagens teóricas, que foram adaptados para incorporar características específicas da crise asiática. Contudo, apesar de os modelos de terceira geração adotarem abordagens analíticas semelhantes, seja à dos modelos de primeira geração, seja à dos modelos de segunda geração, ao nosso ver os novos modelos não se enquadram nessas geraçôes precedentes, pois adotam um esquema explicativo distinto, o que justifica a sua classificação como modelos de terceira geração. Como ressaltado acima, esses modelos podem ser considerados modelos de crises gêmeas, que são provocadas, em última instância, por problemas nos sistemas financeiros "emergentes", enquanto os modelos de primeira e segunda geração são modelos de crises cambiais, associadas à inconsistência dos fundamentos macroeconômicos, "estreitos" ou "ampliados".

22 KRUGMAN (1999) faz uma autocrítica de seu modelo de 1998 e desenvolve um novo modelo inspirado na crise asiática, que enfatiza "the role of companies' balance sheets in determining their ability to invest, and that of capital flows in affecting the real exchange rate." (KRUGMAN, 1999, p. 3). 
del, o ingresso de capitais e o boom na intermediação financeira doméstica são partes integrais de um ataque especulativo totalmente antecipado contra as reservas do governo.

Ou seja, no modelo de Dooley, o conflito de política surgiria em virtude do desejo de um governo sujeito a uma restrição de crédito (credit constrained) de manter reservas como uma forma de auto-seguro e, simultaneamente, de garantir os passivos financeiros dos residentes. A disponibilidade deste seguro criaria um diferencial de rendimento favorável às obrigaçốes emitidas pelos residentes dos países "emergentes” (bancos e empresas não-financeiras), estimulando um ingresso bruto de capitais privados. Dois fatores teriam reduzido a restrição de crédito dos governos desses países nos anos 90: em primeiro lugar, a queda das taxas de juros internacionais em 1989 teria gerado um insurance fund para os "mercados emergentes" devido aos seus efeitos positivos sobre o estoque de dívida externa (obrigações não-contingentes) e, assim, sobre as reservas cambiais líquidas; em segundo lugar, os pacotes de salvamento ao México, Argentina e Tailândia teriam sinalizado aos investidores que esses países poderiam acessar linhas de créditos oficiais (governos do G-7 e organismos multilaterais), que passariam a integrar o insurance fund.

$\mathrm{O}$ ingresso de capitais seria estimulado pelo diferencial de rentabilidade criado pelo insurance fund, mas sua dimensão dependeria do volume de passivos emitidos pelos residentes. Quanto mais deficiente o sistema de supervisão e regulamentação do país (o que seria a regra nos "mercados emergentes"), maior a velocidade de crescimento desses passivos garantidos pelo governo (que constituem os ativos dos investidores externos), os quais correspondem a suas obrigaçôes contingentes. Estes fluxos se manteriam até o momento em que o estoque de reservas internacionais se igualasse a essas obrigações contingentes. Neste momento, aquele diferencial seria eliminado e ocorreria o ataque especulativo antecipado: os investidores venderiam os ativos garantidos ao governo, esgotando as reservas. O regime cambial pode se alterar após o ataque, mas as expectativas quanto à mudança neste regime não são características necessárias da seqüência descrita acima (como nos modelos de primeira e segunda geração). Isto porque o ataque especulativo é sempre um ataque contra as reservas internacionais, que constituem o passivo contingente do governo, independentemente do tipo de regime cambial. Se o país adota um regime de câmbio fixo, este entrará em colapso simultaneamente à reversão dos fluxos de capitais.

De acordo com Dooley, seu modelo fornece uma explicação para uma regularidade empírica das crises dos "mercados emergentes" nos anos 90: os ingressos de fluxos brutos de capitais privados, atraídos pelos diferenciais de rentabilidade, que precederam os ataques especulativos e, assim, essas crises. ${ }^{23}$ Contudo, no seu modelo, o "cul-

23 Vale mencionar que o insurance model oferece, igualmente, uma explicação para o efeito-contágio, outra característica das crises recentes que tem sido objeto de diversos modelos desenvolvidos após a crise asiática. No modelo de Dooley, uma operação de resgate reduziria os recursos oficiais disponíveis e, assim, o insurance fund necessário para financiar outras operações semelhantes, reduzindo a rentabilidade esperada dos investimentos nos "mercados emergentes" e, com isso, resultando num resgate de recursos destes mercados de forma geral. 
pado", em última instância, da crise seria o governo, pois além das distorçôes geradas pelas garantias aos passivos dos residentes, a adoção de um sistema de regulamentação prudencial eficiente impediria o crescimento dos passivos financeiros dos residentes

Assim, nesse primeiro grupo de modelos de terceira geração, as crises continuam sendo o resultado inevitável de um ataque especulativo antecipado contra as reservas do governo, decorrente de uma inconsistência de política interna, como nos modelos de primeira geração. A única e principal diferença é a origem desta inconsistência: nos modelos de primeira geração, as políticas fiscal e monetária expansionistas; nos modelos de terceira geração, a existência de garantias governamentais aos passivos dos residentes, a qual introduziria uma distorção no funcionamento dos mercados, e assim estimularia o ingresso de capitais insustentável, num contexto de regulamentação e supervisão bancárias ineficientes. ${ }^{24}$

No segundo grupo de modelos, a ênfase desloca-se do risco moral para o pânico financeiro dos investidores estrangeiros (sobretudo os bancos internacionais, no caso da Ásia), que se torna um dos determinantes da fragilidade dos sistemas financeiros domésticos. Esses modelos seguem uma abordagem mais próxima dos modelos de segunda geração, na medida em que um dos seus elementos centrais é a existência de profecias auto-realizáveis e a possibilidade de equilíbrios múltiplos.

Radelet \& Sachs (1998) foram os precursores desta abordagem, contudo foram Chang \& Velasco (1998) que modelizaram seus argumentos. Estes autores desenvolvem um modelo, que se propõe a ser um canonical model das crises financeiras nos "mercados emergentes”, a partir da adaptação do modelo de corrida bancária de Diamond \& Dybvig $(1983)^{25}$ para economias abertas com livre mobilidade de capitais. ${ }^{26}$ Este modelo também supõe agentes racionais e informados, mas ao contrário dos modelos do primeiro grupo, há possibilidade de equilíbrios múltiplos, como nos modelos de se-

24 Outro modelo que se enquadraria nesse primeiro grupo é o modelo de overborrowing syndrome de MCKINNON \& PILL (1998, p. 352), no qual "(...) the problem of overborrowing is rooted in an institutional failure to manage the moral hazard problem introduced into the financial system by deposit insurance (...)."

25 No modelo de corrida bancária de DIAMOND \& DYBVIG (1983) a função essencial dos intermediários financeiros seria a transformação de ativos ilíquidos (investimentos produtivos sem risco, mas de longo prazo) em passivos líquidos (depósitos bancários). No entanto, ao cumprirem a função de "transformadores de prazos" e na ausência de esquemas de seguro de depósito, os bancos tornam-se vulneráveis à corrida dos depositantes para retirada dos recursos. Os depositantes podem passar a acreditar que o banco não é seguro e que os demais depositantes resgataráo seus recursos. Assim, se todos adotarem o mesmo comportamento, o banco será forçado a liquidar seu investimento de longo prazo. Mas como o valor liquidado é menor que o volume de saques, ele entra em falência.

26 GOLDFAJN \& VALDÉS (1997) também desenvolvem um modelo a partir da adaptação do modelo de DIAMOND \& DYBVIG (1983) a economias abertas com mobilidade de capitais, contudo não restringem sua análise aos países "emergentes”. Já FURMAN \& STIGLITZ (1998) desenvolvem um modelo que também destaca o pânico dos credores externos como o fator subjacente à crise asiática, mas se baseiam no modelo de racionamento de crédito de STIGLITZ \& WEISS (1981). 
gunda geração. A lógica subjacente é a mesma: a multiplicidade de equilíbrios está associada à possibilidade de ataques especulativos auto-realizáveis, seja contra as reservas do sistema bancário, seja contra as reservas cambiais do banco central. (MARION, 1999).

Assim como no modelo original de Diamond \& Dybvig (1983), os bancos cumprem o papel de transformar ativos ilíquidos em passivos líquidos. No entanto, ao contrário do modelo original, no modelo de Chang \& Velasco (1998) o bem de consumo está disponível no mercado internacional (assim, os consumidores precisam de dólares para adquiri-lo) e os bancos podem se endividar externamente, até um limite determinado de forma exógena (credit ceiling). Assim, ao lado dos depósitos dos agentes domésticos, a segunda fonte de funding dos bancos é o endividamento externo, que amplia os recursos disponíveis para a aplicação na tecnologia de longo prazo. Igualmente, os bancos podem recorrer ao mercado financeiro internacional em caso de uma corrida bancária, o que evitaria a necessidade de liquidar antecipadamente o ativo ilíquido.

Enquanto no modelo de Diamond \& Dybvig (1983) os bancos são vulneráveis somente aos resgates dos depósitos pelos residentes, no modelo de Chang \& Velasco (1998) estes se tornam igualmente vulneráveis ao pânico dos credores externos, que pode resultar numa situação de iliquidez internacional do sistema bancário - definida como um excesso de obrigações reais e potenciais em divisas em relação aos recursos cambiais possíveis de se obter no curto prazo para honrar essas obrigações - e desencadear uma crise bancária, cambial ou gêmea, dependendo do regime de câmbio vigente. ${ }^{27}$

Assim, a iliquidez internacional do sistema bancário pode desempenhar um papel central na eclosão da crise financeira. A fuga dos credores internacionais - seja mediante o resgate de recursos, seja via interrupção da rolagem das dívidas - transforma-se numa profecia auto-realizável devido a falhas de coordenação. Contudo, como nos modelos de segunda geração, o equilíbrio que prevalecerá é indeterminado e sua multiplicidade somente é possível em razão da fragilidade dos fundamentos. Mas neste caso a fragilidade não está associada às elevadas taxas de desemprego e/ou ao estoque elevado de dívida pública, mas decorre da situação de iliquidez do sistema bancário, que o torna vulnerável ao pânico.

27 A forma de manifestação da crise dependerá do regime cambial vigente. Neste artigo, os autores exploram dois casos: um regime de currency board, no qual eclode uma crise bancária; um regime de câmbio fixo com emprestador em última instância, no qual eclode uma crise cambial. Assim, é interessante observar que o caso de crise gêmea, que predominou no sudeste asiático, não é considerado. 
Chang \& Velasco citam alguns fatores que teriam contribuído para agravar a vulnerabilidade dos sistemas bancários dos países “emergentes" nos anos 90. Em primeiro lugar, os fluxos de capitais (que se restringem, nesse modelo, ao endividamento externo), associados à abertura financeira e, em segundo lugar, a tendência de encurtamento dos prazos no mercado financeiro internacional. Estes dois fatores podem ampliar o problema de iliquidez do sistema bancário, sendo que o volume desse endividamento e sua maturidade afetam a vulnerabilidade deste sistema ao pânico dos credores externos. Assim, quanto maior o endividamento externo do sistema bancário e menores os prazos da dívida, maior a sua vulnerabilidade à crise. Ademais, a intermediação dos fluxos de capitais pelos bancos resulta inevitavelmente num boom nos preços dos ativos de oferta inelástica, o qual seria seguido por um crash na ocorrência de um pânico financeiro (na medida em que os bancos teriam que liquidar esses ativos para fazer frente aos resgates dos depositantes ou à fuga dos credores externos), agravando os efeitos deletérios da crise bancária.

Um terceiro fator que teria contribuído para a fragilidade dos sistemas bancários domésticos seria a liberalização financeira doméstica, sobretudo a redução dos encaixes compulsórios, que teria aberto espaço para um maior descasamento dos prazos e para o aumento da competição, que eliminaria os lucros de monopólio do setor. Ou seja, apesar dos efeitos positivos em termos de bem-estar, a liberalização também aumentaria o problema de iliquidez potencial dos bancos.

Os autores também ressaltam o papel dos choques externos e das garantias públicas e subsídios nas crises. No entanto, ambos teriam um papel secundário. Esses choques como uma elevação da taxa de juros externa e, assim, dos encargos da dívida - poderiam tornar os depositantes domésticos e os credores externos mais pessimistas e assim contribuir para o pânico. Neste caso, os efeitos do choque inicial seriam ampliados pela existência do sistema bancário. Em relação às distorçôes introduzidas pelas políticas governamentais, os autores ressaltam que estas podem tornar uma corrida bancária possível na medida em que os subsídios estimulam o investimento no ativo de longo prazo e, assim, o endividamento externo. Contudo, essas políticas são deletérias mais por tornarem os bancos menos líquidos do que por criarem sobreinvestimentos ineficientes (como em KRUGMAN, 1998 e CORSETTI, PESENTI \& ROUBINI, 1998) ${ }^{28}$ e seu papel teria sido superestimado nas crises recentes.

28 CHANG \& VELASCO (1998) também ressaltam que, como os bancos desempenham uma função útil, a crise não é benéfica (como defendido por Krugman e Corsetti Pesenti \& Roubini); pelo contrário, provoca liquidação ineficiente de investimentos e quedas excessivas nos preços dos ativos. 
Mas, por que esse tipo de crise atingiria somente os países "emergentes"? De acordo com Chang \& Velasco (1998), a especificidade desses países seria a predominância dos bancos, decorrente da iliquidez e da shallowness dos mercados de capitais, ou seja, do "subdesenvolvimento" deste mercado, associado aos problemas de assimetria de informação especialmente pronunciados nesses países devido às fragilidades regulatórias e institucionais. Esta predominância justificaria uma característica central do modelo: a ênfase nos fluxos de capitais intermediados pelo sistema bancário, que tornam possível o surgimento da situação de iliquidez internacional deste sistema - condição necessária para a eclosão da crise. Vale lembrar que as distorções associadas às garantias governamentais não são ignoradas, mas têm um papel secundário, ao contrário do que se observa no primeiro grupo de modelos.

O terceiro (e mais recente) grupo de modelos procura integrar num mesmo esquema analítico os dois argumentos mencionados acima. Nesse sentido, Schneider \& Tornell (2000) desenvolvem um modelo no qual as distorções das políticas governamentais (risco moral) e dos mercados (expectativas auto-realizáveis e imperfeição dos contratos) determinam as crises. $^{29}$

Esses autores desenvolveram um modelo de crises gêmeas nos quais os bancos, principal elo de ligação entre o funding externo e o setor produtivo doméstico, estariam expostos a dois tipos de distorçôes do mercado de crédito internacional, cuja interação determinaria, em última instância, o crescimento excessivo do crédito, a apreciação cambial e a auto-realização das crises gêmeas: a existência de mecanismos (explícitos ou não) de proteção aos investidores em caso de crise sistêmica - uma falha governamental - e a já mencionada imperfeição dos contratos (enforceability) - uma falha de mercado.

Em princípio, as duas distorções teriam efeitos opostos sobre a oferta de crédito: enquanto as garantias públicas, fornecidas por uma organização internacional, estimulam o sobreendividamento, problemas no cumprimento dos contratos levam os bancos a racionarem o crédito e, assim, impóem limites ao endividamento. No modelo, como as garantias são acionadas somente em caso de crise sistêmica, sua existência apenas relaxa o racionamento de crédito, mas não o elimina, pois os bancos continuam a se resguardar de riscos não-sistêmicos mediante o controle de oferta de crédito.

29 Além deste modelo, vale mencionar os modelos de BURNSIDE et al. (2000) - que se baseia nos argumentos de KRUGMAN (1998) e CORSETTI, PESENTI \& ROUBINI (1998a), mas também incorpora o papel das expectativas auto-realizáveis, que determinam o momento da eclosão da crise - e de IRWIN \& VINES (1999), que integra as visões de KRUGMAN (1998) e de DOOLEY (1999), assim como a de RADELET \& SACHS sobre o pânico financeiro. 
Adicionalmente, o modelo incorpora dois fatos estilizados, que também estariam presentes nas crises dos anos $90 .{ }^{30}$ Por um lado, o comportamento assimétrico dos setores de bens comercializáveis e não-comercializáveis: este tenderia a apresentar maiores taxas de crescimento antes da crise, mas, em contrapartida, seria atingido de forma mais expressiva pela reversão cíclica e teria uma recuperação mais lenta. Por outro lado, os bancos seriam altamente expostos ao setor de não-comercializáveis, sendo grande parte dos problemas em seus balanços originados dos empréstimos a esse setor.

O modelo descreve a dinâmica de um ciclo de crédito financiado por recursos externos que alavanca o crescimento do setor de náo-comercializáveis e culmina numa crise gêmea. O ponto de partida do boom é a antecipação, por esse setor, de um aumento da demanda pelos seus produtos (associada, por exemplo, aos efeitos das reformas estruturais, como a abertura comercial), que estimula a expansão da capacidade produtiva. Esse aumento é financiado mediante empréstimos dos bancos domésticos, a partir de recursos captados no mercado internacional. A presença de garantias relaxa os limites ao endividamento (associados à imperfeição dos contratos), neutraliza o risco cambial e funciona como um substituto para os colaterais dos tomadores domésticos, incentivando a busca de mais funding externo, que alavanca os investimentos do setor de nãocomercializáveis. ${ }^{31}$ Em seguida, a taxa de câmbio começa a se apreciar - devido à alta dos preços dos bens não-comercializáveis, provocada pelo aumento dos investimentos - com impactos positivos sobre o balanço dos bancos, dada a denominação das dívidas em moeda estrangeira, os quais convertem seu maior fluxo de caixa em empréstimos para o setor não-comercializável, fomentando ainda mais o boom.

Contudo, em um determinado momento do ciclo, o estoque elevado de dívidas denominadas em moeda estrangeira cria uma situação de fragilidade financeira - cuja intensidade depende do nível de endividamento externo e da qualidade dos ativos dos bancos -, tornando a economia vulnerável às crises derivadas de expectativas auto-realizáveis, que em geral têm um caráter gêmeo. Isto porque, como essas dívidas foram contraídas principalmente pelo setor de não-comercializáveis, que não tem receitas em moeda estrangeira, o risco cambial converte-se em risco de crédito, no caso de uma desvalorização provocada pelo ataque especulativo auto-realizável.

Em suma, assim como nos modelos de segunda geração e de Chang \& Velasco, a distorção nos "fundamentos" (neste modelo, as garantias implícitas e a imperfeição no

30 É interessante mencionar que os autores utilizam como exemplo a crise mexicana, ao contrário dos demais modelos de terceira geração, que se referem principalmente à crise asiática.

31 Em condiçôes normais, o ritmo de crescimento desses investimentos dependeria da capacidade de geração de renda dos investimentos passados e da antecipação da evolução futura da demanda de bens finais, e a oferta de crédito seria limitada pela existência de colaterais. Assim, a existência de garantias governamentais e a liberalização financeira aliviariam a restrição orçamentária "normal" do setor de não-comercializáveis. 
cumprimento dos contratos) conduzem a economia para a região "frágil”, neste caso, para uma situação da fragilidade financeira, condição necessária, mas não suficiente, para a crise. A sua eclosão ou não é indeterminada e depende das expectativas dos agentes, que podem se coordenar no equilíbrio com ou sem ataque especulativo.

No modelo de Schneider \& Tornell (1999), a maior vulnerabilidade dos países "emergentes" às crises "auto-realizáveis" também decorreria de uma característica institucional dos seus sistemas financeiros: a inexistência de uma regulação prudencial eficiente. Nos países desenvolvidos, nos quais também haveria garantias implícitas às instituições maiores (política too-big-to-fail), essa regulação inibiria as posturas especulativas dos bancos, e assim impediria a emergência de situaçôes de fragilidade financeira. Nos termos dos autores: "the unchecked effects of guarantees is what makes emerging economies special.” (SCHNEIDER \& TORNELL, 1999, p. 7).

\section{CONSIDERAÇÕES FINAIS}

Nas seções precedentes, procurou-se mostrar que após as crises mexicana e asiática ocorreu uma verdadeira "reação teórica" no âmbito do pensamento convencional sobre crises financeiras nos países "emergentes". As sucessivas geraçóes de modelos que emergiram na segunda metade dos anos 90 incorporaram no seu esquema analítico vários fatores externos aos países, que caracterizaram a dinâmica do sistema financeiro internacional nesse período, entre os quais: os ataques especulativos auto-realizáveis, a volatilidade dos fluxos de capitais, o comportamento de manada dos investidores estrangeiros e o efeito-contágio.

Esta "reação teórica" representou um importante avanço da literatura convencional sobre crises financeiras. A recorrência desses fenômenos nos anos 90, associada ao aprofundamento da instabilidade financeira internacional, e a sucessão de crises financeiras em países com sólidos fundamentos fiscais e monetários explicitaram a inadequação do modelo de primeira geração, hegemônico até então.

Os novos modelos também avançaram no sentido de incorporar uma importante regularidade das crises financeiras dos países “emergentes” nos anos 90: o seu caráter gêmeo. Os modelos de segunda geração, pós-crise mexicana, deram o primeiro passo nessa direção, ao destacarem o vínculo entre, de um lado, o ingresso de capitais e a liberalização financeira doméstica e, de outro, a fragilidade bancária, bem como a relação entre esta fragilidade e a crise cambial. Mas nesses modelos essa relação é indireta, pois a fragilidade bancária constitui um dos fundamentos "ampliados", ao lado do elevado estoque de dívida pública de curto prazo, cuja deterioração reforça a tensão entre 
os múltiplos objetivos do governo, conduzindo o país para a região frágil, na qual os ataques especulativos auto-realizáveis são possíveis.

Somente nos modelos de terceira geração, pós-crise asiática, a interação entre as crises cambiais e bancárias é explicitamente considerada. Além de examinarem de forma mais detalhada aquele vínculo - ou seja, os efeitos deletérios dos fluxos de capitais e da liberalização financeira sobre os sistemas bancários domésticos -, nesses modelos a relação entre a crise cambial e fragilidade bancária torna-se direta e são exploradas as características específicas dos sistemas financeiros “emergentes” subjacentes a esta fragilidade.

Ao inserir essas características no seu esquema analítico, os modelos de terceira geração também preencheram uma importante lacuna da geração precedente, qual seja, explicar os determinantes da maior vulnerabilidade desses países às crises financeiras, especialmente gêmeas, vis-à-vis aos países desenvolvidos. Nos modelos de segunda geração, tanto países "emergentes" quanto países desenvolvidos seriam, da mesma forma, vulneráveis aos ataques especulativos auto-realizáveis. Uma análise superficial poderia dizer que a diferença estaria na origem do dilema da política: no caso dos países europeus, o desemprego, a baixa taxa de crescimento e as "incertezas" em relação ao tratado de Maastrïch, e no caso do México - e dos países "emergentes" em geral - o elevado estoque de dívida pública e a fragilidade do sistema bancário. Contudo, esta explicação não se sustenta. Como mencionado na seção 2 , os fundamentos "ampliados” dos modelos de segunda geração pós-crise do México já haviam sido considerados pelos modelos pós-crise do SME.

Nos três tipos de modelos de terceira geração a maior vulnerabilidade dos países "emergentes" às crises gêmeas decorreria de fragilidades específicas dos seus sistemas financeiros. Enquanto no primeiro grupo é enfatizado o papel do risco moral associado à existência de garantias governamentais aos passivos dos residentes, no segundo grupo (modelo de CHANG \& VELASCO, 1998) destaca-se a predominância dos bancos nesses sistemas, decorrente do subdesenvolvimento dos mercados de capitais, relacionado, por sua vez, às fragilidades regulatórias e institucionais. Já no terceiro grupo, mais especificamente no modelo de Schneider \& Tornell (2000), a origem da fragilidade seria a regulação prudencial deficiente, que permitiria a emergência de situaçôes de fragilidade financeira num contexto de existência daquelas garantias.

Na realidade, a introdução de características específicas dos sistemas financeiros dos países "emergentes" nos modelos - que pode ser considerada uma outra dimensão da "reação teórica” - acaba deslocando o foco da análise, mais uma vez, para as fragilidades ou desequilíbrios internos aos países, agora associados não mais à inconsistência dos fundamentos "estreitos" ou "ampliados", mas às distorçôes geradas pelas garantias governamentais ou pelas deficiências regulatórias e/ou institucionais. Em outras palavras, 
nos modelos de terceira geração, a maior vulnerabilidade dos países "emergentes" às crises - associadas aos ataques especulativos auto-realizáveis, ao comportamento de manada dos investidores estrangeiros, à volatilidade dos fluxos de capital - continua sendo atribuída, em última instância, aos fatores internos aos países.

Assim, depara-se com um argumento semelhante ao defendido por McKinnon (1988) na sua autocrítica, que ficou conhecido como o argumento do sequencing (ou "teoria da seqüência”), atualmente um consenso no âmbito do mainstream da Economia e dos organismos multilaterais, qual seja: a abertura financeira completa, além de constituir a última etapa do processo de liberalização, pode demandar um longo período de tempo para ser implementada, que seja suficiente para a superação das fragilidades dos sistemas financeiros a partir do aperfeiçoamento da sua "infra-estrutura" e do aprofundamento financeiro interno. Neste intervalo, admite-se a possibilidade de imposição de controles sobre os fluxos de capitais. Ou seja, essas especificidades dos sistemas financeiros "emergentes" seriam, em grande medida, "conjunturais" (como os desequilíbrios macroeconômicos) e passíveis de correção à medida que esses países adotassem mecanismos de supervisão e regulamentação bancária, sistemas jurídicos, padrões de disclosure e de auditoria vigentes nos países industrializados e atingissem o grau de desenvolvimento financeiro desses países.

\section{REFERÊNCIAS BIBLIOGRÁFICAS}

AGÉNOR, Pierre-Richard; BHANDARI, J. S.; FLOOD, R. P. Speculative attacks and models of balance of payments crises. IMF Staff Papers, Washington, D.C, v. 39, p. 357-94, Jun. 1992.

AKYÜZ, Y. On financial openess in developing countries. Genebra: UNCTAD, 1992 (Trabalho não publicado).

BERG, Andrew et al. Anticipating balance-of-payments crises. Washington D.C.: International Monetary Fund, 1999 (IMF Occasional Papers n.186).

BURNSIDE, Craig; EICHENBAUM, Martin; REBELO, Sergio. On the fundamentals of self-fulfilling speculative attacks. Cambridge, Mass.: National Bureau of Economic Research, 2000 (NBER Working Paper n. 7554).

CALVO, Guilhermo A.; MENDOZA, Enrique G. Rational herding behavior and the globalization of securities markets. Institute of Empirical Macroeconomics, Federal Bank of Minneapolis, 1997. (Discussion Paper n. 120).

. Mexico's balance-of-payments crisis: a chronicle of a death foretold. Journal of International Economics, n. 41, p. 235-264, 1996.

CALVO, G. A. et al. Foreword. Joumal of International Economics, n. 41, p. 220222, 1996. 
CANUTO, Otaviano; CURADO, Marcelo. Modelos de crises cambiais de 'terceira geração' versus fatos estilizados na América Latina. Economia e Sociedade, Campinas, n. 16, p. 43-65, 2001.

CAPRIO Jr., Gerard; KLINGEBIEL, Daniela. Bank insolvency: bad luck, bad policy, or bad banking? In: BRUNO, Michael; PLESKOVIC, Boris. Annual World Bank Conference on Development Economics, Washington, D. C, 1996, p. 69-104.

CHANG, R; VELASCO, A. Financial crises in emerging markets: a canonical model. Federal Reserve Bank of Atlanta, 1998 (Working Paper n. 98-1).

COLANDER, D.; HOLT, R.; ROSSER, B. The changing face of mainstream economics. Department of Economics, Middleburry College, Middlebury, Vermont, 2003 (Discussion Paper n. 03-27).

COLE, H. L.; KEHOE, T. J. Self-fulfilling debt crises. Joumal of International Economics, n. 41, p. 309-330, 1996.

CORSETTI, Giancarlo; PESENTI, Paolo; ROUBINI, Nouriel. Paper tigers? A model of the Asian crisis. Cambridge: National Bureau of Economic Research, Nov., 1998 (NBER Working Paper Series n. 6783).

CUNHA, André Moreira; PRATES, Daniela Magalhães. Instabilidade e crises: os avanços teóricos e as limitações políticas para o desenvolvimento dos países periféricos. In: FERRAZ, J. C; CROCCO, M; ELIAS, L. A. Liberalização econômica e desenvolvimento: modelos, políticas e restrições. São Paulo: Futura, 2003.

. Instabilidade e crises nos anos 90: a reação conservadora. Revista Economia Ensaios, Uberlândia: Departamento de Economia da UFU, v. 15, n. 2, p. 151-186, 2001.

DEMIRGÜÇ-KUNT, Ash; DETRAGIACHE, Enrica. The determinants of banking crises in developing and developed Countries. IMF Staff Papers, Washington D.C., v. 45, n. 1, Mar., 1998.

DIAMOND, Douglas W.; DYBVIG, Philip H. Bank runs, deposit insurance, and liquidity. Journal of Political Economy, v. 91, n. 31, p. 401-419, 1983.

DIAZ-ALEJANDRO, Carlos. Good-bye financial repression, hello financial crash. Journal of Development Economics, v. 19, p. 1-24, 1985.

DOOLEY, Michael. A model of crises in emerging markets. Cambridge, Mass.: National Bureau of Economic Research, Dec., 1997 (NBER Working Paper n. $6300)$.

EICHENGREEN, Barry. Toward a new international financial architecture: a practical post-Asia agenda. Washington D.C: Institute for International Economics, 1999.

EICHENGREEN, Barry; ROSE, Andrew K.; WYPLOSZ, C. Exchange market mayhem: the antecedents and the aftermath of speculative attacks. Economic Policy, v. 21, p. 249-296, 1995. 
FELIX, D. Mobilité financière internationale: effets déstabilisateurs et régulation. Revue Tiers Monde, t. XXXV, n. 139, 1994.

FLOOD, R.; GARBER, P. Collapsing exchange rate regimes: some linear examples. Journal of International Economics, v. 17, p. 1-13, Aug. 1984.

FLOOD, Robert; MARION, Nancy. Perspectives on the recent currency crisis literature. Cambridge, Mass.: National Bureau of Economic Research, 1998 (NBER Working Paper n. 6380).

. Speculative attacks: fundamentals and self-fulfilling prophecies. Cambridge, Mass.: National Bureau of Economic Research, 1996 (NBER Working Paper n. 5789).

FRANKEL, Jeffrey A.; ROSE, Andrew. Currency crashes in emerging markets: an empirical treatment. Journal of International Economics, n. 41, p. 351-366, 1996.

FURMAN, J.; STIGLITZ, J.E. Economic crises: evidence and insights from East Asia. Brookings Papers on Economic Activity, Washington D. C, n. 2, p. 1-135, 1998.

GOLDFAJN, I.; VALDÈS, R. Capital flows and the twin crises: the role of liquidity. Washington D.C.: International Monetary Fund, 1997 (IMF Working Paper n.87).

IRWIN, G; VINES, D. A Krugman-Dooley-Sachs third generation model of the Asian financial crisis. Global Economic Institutions Working Paper Series, n. 46, Dec. 1999.

JEANNE, Olivier. Les modèles de crise de change: un essai de synthèse en relation avec la crise du franc de 1992-93. Économie et Prévision, n. 123-124, p. 147$162,1996$.

KRUGMAN, Paul. Balance sheets, the transfer problem, and financial crisis. 1999 (Trabalho não publicado).

. What happened to Asia?1998 (Trabalho não publicado).

. A model of balance of payments crises. Journal of Money, Credit and Banking, v. 11, n. 3, p. 311-325, Aug. 1979.

MASSON, Paul R. Multiple equilibria, contagion and the emerging market crisis. Washington, D.C: International Monetary Fund, 1999 (IMF Working Paper n. 164).

MARION, Nancy P. Some parallels between currency and banking crises. In: ISARD, Peter; RAZIN, Assaf; ROSE, Andrew K. (eds.), International finance and financial crises: essays in honor of Robert P. Flood. Norwell, Massachusetts: Kluwer Academic Publishers, 1999.

MCKINNON, R. I. Financial liberalization and economic development. International Center for Economic Growth, 1988. 
MCKINNON, R. I.; PILL, Huw. The overborrowing syndrome: are East Asian economies different? In: GLICK, R., Managing capital flows and exchange rates: perspectives from the Pacific Basin. Cambridge: Cambridge University Press, 1998.

MISHKIN, Frederic S. Understanding financial crises: a developing country perspective. Cambridge, Mass.: National Bureau of Economic Research, 1996 (NBER Working Paper n. 5600)

OBSTFELD, Maurice. The logic of currency crises. Cabiers Economiques et Monétaires n. 43. Paris: Banque de France, 1994.

. Rational and self-fulfilling balance of payments crises. American Economic Review, v. 76, p. 72-81, 1986.

RADELET, S; SACHS, J. The onset of the East Asian financial crisis. Cambridge, Mass.: National Bureau on Economic Research, 1998 (NBER Working Paper n. 6680).

SACHS, Jeffrey; TORNELL, Aarón; VELASCO, Andrés. The Mexican peso crisis: sudden death or death foretold? Journal of International Economics, n. 41, p. 265-283, Dec. 1996a.

. The collapse of the Mexican Peso: what we have learned?. Economic Policy, v. 22, p. 15-63, Apr. 1996b.

SALANT, Stephen; HENDERSON, Dale W. Market anticipation of government policy and the price of gold. Journal of Political Economy, v. 86, p. 627-48, Aug. 1978.

SCHNEIDER, Martin; TORNELL, Aaron. Balance sheet effects, bailout guarantees and financial crises. Cambridge, Mass.: National Bureau of Economic Research, 2000 (NBER Working Paper n. 8060).

SHEFFRIN, Steven. Rational expectations. Cambridge: Cambridge University, 1983.

SHOR, J. B. Introduction. In: SHOR, J. B.; BANURI, T. (eds.), Financial openness and national autonomy. $1^{\mathrm{a}}$ edição. Oxford: Claredon Press, 1992.

STIGLITZ, J. E.; WEISS, A. Credit rationing in markets with imperfect information. The American Economic Review, v. 71, n. 3, 1981.

VELASCO, Andrés. Financial crises and balance of payment crises: a simple model of the Southern Cone experience. Joumal of Development Economics, v. 27, p. 263-83, Oct. 1987.

WYPLOSZ, Charles. Globalized financial markets and financial crises. In: CONFERENCE ON COPING WITH FINANCIAL CRISES IN DEVELOPING AND TRANSITION COUNTRIES, Amsterdam, March, 1998.

Agradeço às sugestões pertinentes de um dos pareceristas anônimos.

(Recebido em fevereiro de 2004. Aceito para publicação em janeiro de 2005).

Est. econ., São Paulo, 35(2): 359-385, abr-jun 2005 